\title{
A Study on Procurement Function of Supply Chain Management in Small and Medium-Sized Enterprises in Pokhara Valley
}

\author{
Rajesh Kumar Thagurathi
}

\begin{abstract}
This paper has examined existing procurement practices, in the context of supply chain management, adopted by the Small and Medium-Sized Enterprises (SMEs) in Pokhara valley. The paper explored status of procurement section in the various organizations, examines the extent to which the information and communication technologies have been used for procurement, and presents the views of procurement personals on the impact of customer-supplier relationships on procurement function in formulating Supply Chain Management (SCM) initiatives. It has identified the potential paths for SMEs to improve their procurement practices.
\end{abstract}

Keywords: supply chain management, procurement, small and medium-sized enterprises

\section{Introduction}

Business is becoming increasingly competitive and needs to find creative ways to operate as efficiently as possible. Delivering quality products to customers at the right time, at the right place, and at the right price has become a new challenge. The supply chain management (SCM) approach has thus increasingly been given prominence by many organizations as an opportunity to achieve these goals. Firms are effectively using new information technologies like the Internet and wireless telecommunications to improve service and delivery processes. Through secure intranet systems and business-to-business (B2B) ecommerce platforms, the focus is on improving information management: integrating internal systems with external partners.

Supply chain management encompasses all activities associated with a firm moving its composite flow of information, materials and services from the raw material stage through production and on to the end customer. This includes sourcing and procurement, production scheduling, order processing, inventory management, transportation, manufacturing, warehousing, customer service and information system used to monitor the activities (Lankford, 2004). The efficiency and effectiveness of a supply chain is contingent on the ability to gather and analyze important information through these components. The single most important ingredient for successful supply chain management is a trust worthy relationship between the partners in the supply chain. Each party in the supply chain must have mutual confidence in the other members' capabilities and actions.

Procurement is concerned with the acquisition of suppliers' goods and resources, in order to contribute to administrative and strategic objectives of the organization. In practice, purchasing managers have to respond creatively to internal customers' need on the one hand and maintain a mutually profitable relationship with suppliers on the other (Fung, 1999). The traditional view is that purchasing is primarily a cost reduction function, affecting directly a firm's profit and return-on-asset and hence it's competitive position in industry. Pinkerton (2001) mentioned that the procurement would have to be proactive and strategic and move from exchange thinking to a long-term relationship. Long-term relationships, 
partnerships, and alliances can only be achieved by reducing the number of suppliers, i.e., purchases must be consolidated, standardized, and simplified in order to increase the value or importance of the relationship. We must always remember that price is just a component of cost. Therefore, the focus of procurement must be on a long-term relationship with fewer suppliers based on trust or win-win negotiation philosophy and sharing of confidential information.

\section{Background Information}

In 1997, the Government of Nepal amended the industrial policy of 1992, categorizing industries with fixed investment up to Rs.30 million as small industries and fixed investment between Rs. 30 million and Rs.100 million as medium industries. Fixed investments of more than Rs.100 million are categorized as large industries. Adhikari and Pradhan (2001) described that SMEs account for 99 percent of the total industrial establishment in the country. SMEs provide job opportunities to 498 thousand people, accounting for more than 90 percent of the employment opportunity in the total industrial sector. SMEs account for 41 percent of the total fixed capital outlay of the industry sector. The export manufactured goods accounted for more than 80 percent of the total export and SMEs share to GDP is 9.22 percent.

Pokhara city located in the middle part of Nepal, the head quarter of the Western Region of the country, is considered one of the major industrial cities. Business activities in Pokhara centers on retail-trading and whole-sale of various consumer goods and industrial items; production of noodles, confectionary items, packaging items, plastic items, garments, carpets, bricks; and processing of agricultural produce etc. There are few major enterprises, about 150 SMEs, involved in manufacturing, trading, and service sectors.

\section{Theoretical Framework}

Literature study reveals that the strategic procurement practices can be best measured with the help of the following factors.

- Buyer-supplier relationships

- Implementation of information and communication technologies

Fynes and Voss (2002) described that the buyer-supplier relationships can be measured with the help of the factors like trust, adaptation, communication, interdependence, commitment, satisfaction, and cooperation. Adoption of information communication technologies in supply chain management can be captured by collecting the information to the extent of application of the following tools in buyer supplier interaction like, Telephone, Fax, E-mail, Internet, Intranet, SCM software, Enterprises Resources Planning (ERP), Electronic Data Interchange (EDI), Bar-coding, and Scanning.

\section{The Study Method}

This is the first study of this type conducted in Pokhara valley; therefore, exploratory research design was used. Information related to Supply Chain Management of the SMEs was gathered with the help of structured questionnaire. Besides the questionnaire personal discussions were made with the owner/ proprietor/ chief executive officer (CEO)/ procurement officer.

\section{Data Presentation and Analysis}


The sample size of this study consists of 33 enterprises of Pokhara valley. Out of them 13 are manufacturing industries, 8 are involved in wholesale business and remaining 12 are related to retail business. Retail business sector comprises of few departmental stores also. The data encompasses the organizations which are newly established (just 2 years old) to those having long duration of business experiences (up to 32 years in operations). Most of the respondents ( $79 \%$ of the total) are the owner of the respective organizations and the mean of the working experience of the respondents is 11 years.

\subsection{Procurement Activities in SMEs}

The organizational structure of firms has been analyzed with reference to the procurement activities and existence of separate procurement department. If we see businesswise, almost half of the organizations involved in manufacturing and around $20 \%$ of the retail businesses do have separate procurement department while none of the organizations involved in wholesale have such arrangement. During the interview, it was found that, in majority of the SMEs in Pokhara, the owners themselves are involved in major procurement activities.

The competitive bidding practice (i.e. inquiring the prices of the products at prospective suppliers through formal quotations or telephone or fax or email before placing an order) in SMEs have been studied. The study revealed that the majority of the organizations involved in manufacturing and retail-trading sectors adopt competitive bidding occasionally while majority of the organizations involved in wholesale business adopt competitive bidding usually.

\subsection{Supplier Selection \& Retention Practices in SMEs}

Purchasing a quality product is the main job of the procurement function. Besides owning quality product, the SMEs rated the various other aspects in five point scale regarding supplier selection/retention. The priority given to each factor by the respondents is given in the following table 5.1.

Table 5.1 Weightage Given to Various Dimensions by the Respondents

\begin{tabular}{|l|c|c|c|c|c|}
\hline \multicolumn{1}{|c|}{ Dimensions } & Very Low & Low & Moderate & High & Very High \\
\hline a) Competitive Price & $0 \%$ & $0 \%$ & $6.1 \%$ & $33.3 \%$ & $\mathbf{6 0 . 6 \%}$ \\
\hline b) Order cycle time & $0 \%$ & $9.1 \%$ & $3.0 \%$ & $\mathbf{5 1 . 5 \%}$ & $36.4 \%$ \\
\hline c) Order fill rate & $0 \%$ & $6.1 \%$ & $\mathbf{4 2 . 4 \%}$ & $39.4 \%$ & $12.1 \%$ \\
\hline d) On time delivery & $0 \%$ & $3.0 \%$ & $15.2 \%$ & $39.4 \%$ & $\mathbf{4 2 . 4 \%}$ \\
\hline e) Ordering convenience & $0 \%$ & $3.0 \%$ & $12.1 \%$ & $39.4 \%$ & $\mathbf{4 5 . 5 \%}$ \\
\hline f) Delivery reliability & $0 \%$ & $0 \%$ & $9.1 \%$ & $36.4 \%$ & $\mathbf{5 4 . 5 \%}$ \\
\hline g) Documentation quality & $0 \%$ & $6.1 \%$ & $21.2 \%$ & $33.3 \%$ & $\mathbf{3 9 . 4 \%}$ \\
\hline h) Technical support & $\mathbf{3 3 . 3 \%}$ & $9.1 \%$ & $\mathbf{3 3 . 3} \%$ & $18.2 \%$ & $6.1 \%$ \\
\hline i) Flexibility & $0 \%$ & $0 \%$ & $\mathbf{4 8 . 5 \%}$ & $39.4 \%$ & $12.1 \%$ \\
\hline j) Claim procedure & $0 \%$ & $0 \%$ & $21.2 \%$ & $\mathbf{4 2 . 4 \%}$ & $36.4 \%$ \\
\hline k) Location & $3.0 \%$ & $24.2 \%$ & $30.3 \%$ & $\mathbf{3 6 . 4 \%}$ & $6.1 \%$ \\
\hline 1) Suppliers' reputation \\
and financial stability
\end{tabular}


The above table shows that while selecting the new suppliers and in the stage of whether to further continue the relation with the particular supplier or not, most of the enterprises have given 'very high' priority to factors like, competitive prices, on time delivery, ordering convenience, delivery reliability, documentation quality, past experience with the particular supplier and so on. Thus, the above information could be very useful for those enterprises which are involved in $\mathrm{B} 2 \mathrm{~B}$ transaction. Beside those factors, during the interaction some of the respondents have identified the issues like, personal behavior of the supplier, length of credit facility, after sales service in the case of damaged product, brand image of the product and quantity discount also play vital role for extending the relation with the particular supplier.

\subsection{Relationship Between SMEs and the Suppliers}

The depth of trustworthy relationships between buyers and suppliers is measured with the help of different established factors like, trust, communication, satisfaction, and cooperation etc.

Table 5.2 Indicators of Buyer-Supplier Relationship

\begin{tabular}{|l|l|l|l|}
\hline \multicolumn{1}{|c|}{ Aspect } & \multicolumn{1}{|c|}{$\mathbf{1}$} & \multicolumn{1}{c|}{$\mathbf{2}$} & \multicolumn{1}{|c|}{} \\
\hline $\begin{array}{l}\text { a) Number of suppliers for the } \\
\text { particular product }\end{array}$ & Many & Moderate & One or few \\
\hline b) Length of the relationship & $\begin{array}{l}\text { Brief } \\
\text { (less than 1 year) }\end{array}$ & $\begin{array}{l}\text { Moderate } \\
\text { (less than 2 years) }\end{array}$ & $\begin{array}{l}\text { Long-term } \\
\text { (more than 2 years) }\end{array}$ \\
\hline c) Low price & Major consideration & & Moderately importan \\
\hline $\begin{array}{l}\text { d) Openness with supplier } \\
\text { (information sharing, feedbacks) }\end{array}$ & Low & Moderate & High \\
\hline e) Product quality reliability & $\begin{array}{l}\text { Unreliable, our } \\
\text { company inspects }\end{array}$ & Moderate & $\begin{array}{l}\text { At the source; } \\
\text { Vendor certified }\end{array}$ \\
\hline f) Volume of business & $\begin{array}{l}\text { Low due to many } \\
\text { suppliers }\end{array}$ & Moderate High \\
\hline
\end{tabular}

Respondents were asked to find their organization's existing policies towards the different aspects given in table 5.2, where 1 stands for adversarial relationship, 2 stands for moderate situation, and 3 stands for partnership type relationship with the suppliers. Respondents' responses towards these aspects are given in the table 5.6. It shows that the number of SMEs having many suppliers is slightly higher than those having moderate number of suppliers and one or few for the same product. The modern theory says that limited number of suppliers with trust worthy and long term relationship is beneficial than the large number of supplier base. The data shows that almost $75 \%$ of the SMEs have long term relationships with their suppliers, which is a positive indication for better relationship. Low price is a major consideration of almost $35 \%$ of the respondents. According to modern theories, though purchasing the products at lower price is one of the components of the higher profit margin but it is not the only component of the higher profit margin. During interview the researcher has found this fact has been understood by only some of the respondents.

Information sharing between buyer and supplier is one of the key points of better supply chain management; this fact has been well understood by most of the respondents, 
though they do not rely upon single supplier. Regarding product quality reliability, most of the respondents have mentioned that they have to check the quality and quantity of majority of the items when they receive delivery from suppliers. This is because of the involvement of intermediaries like, workers at suppliers, workers of Transportation Company, etc., however, few number of the respondents have mentioned that of suppliers knowingly tend to push the products which are in over stock. Regarding volume of business the data indicates good relationship between buyer and supplier.

\subsection{Supplier Rating Information}

Information regarding the performance level of the existing suppliers, reasons for changing suppliers etc. are gathered. Respondents rated their existing suppliers' performance on the various dimensions as shown in table 5.3. During the interview, some of the respondents have mentioned that the claim procedure in the case of damaged product delivered should be simpler.

Table 5.3 Respondents' Rating on Suppliers' Performance

\begin{tabular}{|l|c|c|c|c|c|}
\hline \multicolumn{1}{|c|}{ Dimensions } & Very Low & Low & Moderate & High & Very High \\
\hline Delivery quality product & $0.0 \%$ & $0.0 \%$ & $33.3 \%$ & $\mathbf{5 7 . 6 \%}$ & $9.1 \%$ \\
\hline On time delivery & $0.0 \%$ & $3.0 \%$ & $33.3 \%$ & $\mathbf{5 1 . 5 \%}$ & $12.1 \%$ \\
\hline Quantity discount & $3.0 \%$ & $30.3 \%$ & $\mathbf{4 5 . 5 \%}$ & $21.2 \%$ & $0.0 \%$ \\
\hline
\end{tabular}

All the SMEs are found to have more than one supplier for the same product. The following are the four major benefits of multi-supplier.

a) Quantity advantage (i.e., single supplier can't supply the required amount of product)

b) Cost advantage (i.e., they can check the cost of the product at different places and wherever they find cheaper they can place the order)

c) Location advantage (i.e., the supplier which is nearer to the enterprise location is more beneficial and convenient)

d) Quality advantage (i.e., the suppliers are not consistent with respect to the quality of the product they supply)

Among others, the respondents were asked to rank as $1^{\text {st }}, 2^{\text {nd }}, 3^{\text {rd }}$ and $4^{\text {th }}$ benefit from the above four options; the responses are given in the table 5.4. Apart from these, few respondents have mentioned that they can get more credit facility if they have more suppliers.

Table 5.4 Respondents' Rating on Benefits of Having More than One Supplier

\begin{tabular}{|l|c|c|c|c|}
\hline & First Rank & Second Rank & Third Rank & Fourth Rank \\
\hline Quantity advantage & 6 & 5 & $\mathbf{6}$ & 4 \\
\hline Cost advantage & $\mathbf{1 9}$ & 6 & 2 & 0 \\
\hline Quality advantage & 6 & $\mathbf{1 7}$ & 3 & 1 \\
\hline Location advantage & 1 & 4 & $\mathbf{7}$ & 3 \\
\hline
\end{tabular}

The study also revealed that around $55 \%$ of the respondents change the supplier rarely, $42 \%$ occasionally, and remaining frequently. If we see business-wise, the tradition of changing supplier is higher in wholesale business vis-à-vis manufacturing and retail businesses. 


\subsection{Information and Communication Technologies in SMEs}

The survey then looks into the use of specific mode of information \& communication technologies (ICT) in supplier interaction on a five-point scale from 'to no extent' to 'always'. The results are shown in the following table which shows that telephone is the most frequently used mode of communication as almost $90 \%$ of the SMEs using it always with suppliers. While the SMEs are not aware of the modes like, ERP, EDI, and SCM software.

Table 5.5 Application of ICT in Business

\begin{tabular}{|l|c|c|c|c|c|}
\hline \multirow{2}{*}{ Mode } & To no Extent & To a Little Extent & To Some Extent & To a Great Extent & Always \\
\cline { 2 - 6 } & $\%$ & $\%$ & $\%$ & $\%$ & $\%$ \\
\hline Courier service & 30.3 & 24.2 & 42.4 & 0.0 & 3.0 \\
\hline Telephone & 0.0 & 3.0 & 0.0 & 9.1 & 87.9 \\
\hline Fax & 27.3 & 21.2 & 18.2 & 24.2 & 9.1 \\
\hline e-mail & 60.6 & 6.1 & 21.2 & 12.1 & 0.0 \\
\hline SCM Software & 100.0 & 0.0 & 0.0 & 0.0 & 0.0 \\
\hline ERP & 100.0 & 0.0 & 0.0 & 0.0 & 0.0 \\
\hline EDI & 100.0 & 0.0 & 0.0 & 0.0 & 0.0 \\
\hline
\end{tabular}

\subsection{Impact of Customer-Supplier Relationships on Business}

Respondents have expressed their views, according to their past experience, towards the impact of better customer-supplier relationships on the various aspects of their business as shown in the table 5.6 which shows that the majority of the respondents are aware of the benefits like better services, quality products, faster delivery, lower cost, higher customer satisfaction, higher reliability, etc. as the output of better customer-supplier relationships.

Table 5.11 Impact of Better Customer-Supplier Relationship on Business

\begin{tabular}{|l|c|c|}
\hline \multicolumn{1}{|c|}{ Dimensions } & Yes & No \\
\hline Better service/product quality & $84.8 \%$ & $15.2 \%$ \\
\hline Faster delivery & $97.0 \%$ & $3.0 \%$ \\
\hline Lower cost & $75.8 \%$ & $24.2 \%$ \\
\hline Higher customer satisfaction & $84.8 \%$ & $15.2 \%$ \\
\hline Lower inventory & $66.7 \%$ & $33.3 \%$ \\
\hline Higher reliability & $84.8 \%$ & $15.2 \%$ \\
\hline Higher profit & $60.6 \%$ & $39.4 \%$ \\
\hline
\end{tabular}

\section{Conclusion}

Most of the SMEs are still running as one-man organizations since the owner himself or herself is involved in major activities of the organization. Beside qualitative products, low cost is the major concern of the enterprises while selecting the suppliers. During the interaction, majority of the respondents have revealed the fact that they have to check the prices at various suppliers before placing final order to the particular supplier. A separate study is required regarding the consistency of the suppliers with respect to price and quality of the product delivered. Almost $40 \%$ of the enterprises have many suppliers of the same products; enterprises are adopting multi-supplier strategy because of the cost benefits and credit benefits. 
Majority of the respondents have mentioned that they have to check the product quality and quantity of every delivery they receive from suppliers except the case of standard packs. According to the respondents this situation may arise because of the involvement of intermediaries like, workers of supplying agency, workers of transporting company etc. A separate study is required to check whether the personnel working at suppliers' office and Transportation Company are really careless.

Nearly half of the enterprises change suppliers rarely whereas the remaining portion does it occasionally. Majority of the SMEs share information related to product quality and feedbacks, if any, with their suppliers. However, they do not know the major things (internal information) of each other. Almost all the enterprises are using telephone as a key tool for communication. Few of them are also using e-mail for business transactions. Majority of the respondents are aware of the benefits like better services, quality products, faster delivery, lower cost, higher reliability, etc. as the output of better customer-supplier relationships.

\section{Recommendations}

Majority of the enterprises are found to have large number of supplier-base. The focus of procurement must be on a long-term relationship with fewer suppliers based on trust or win-win negotiation philosophy and sharing of confidential information. Thus these enterprises should focus on limited number of suppliers and long term and trustworthy relationships with them.

This study has revealed that the most of the enterprises are using only telephone as a mode of communication while other modes like e-mails and faxes are used by limited number of enterprises. However, the modes like SCM software systems, internet, intranet, ERP and EDI are not used. Since IT is one of the key tools for efficient and effective logistics system, therefore, SMEs must allocate some portion of their budget for the investment in ICT.

\section{REFERENCES}

Adhikari, S. \& Pradhan, D. B. (2001). Paper presented on Symposium on Supply Chain Management for Small and Medium Enterprises. Taipei, Republic of China, 11-14 December 2001

Chin, K., Tummala, V., Leung, J. \& Tang, X. (2004). A study on Supply Chain Management Practices: The Hong Kong Manufacturing Perspective. International Journal of Physical Distribution and Logistics Management, 34(6), 505-524.

Christopher, M. (1998). Logistics and Supply Chain Management. Pearson Education Ltd., India

Fung, P. (1999). Managing purchasing in a supply chain context- evolution and resolution. Logistics Information Management, 12(5), 362-366.

Fynes, B., and Voss, C. (2002). The Moderating Effect of Buyer Supplier Relationship on Quality Practice and Performance, International Journal of Operations \& Production Management, 22(6), 589-613.

Msimangria, K. A. B. (2003). Purchasing and Supply Chain Management Practice in Botswana. Supply Chain Management: an International Journal, 8(1), 7-11.

Lankford, W. M. (2004). Supply Chain Management and the Internet. Online Information Review, 28(4), 301-305.

Lancioni, R. A., Smith, M. F. \& Oliva, T. A. (2000). The Role of the Internet in Supply Chain Management. Industrial Marketing Management, 29, 45-56. 
Mol, M. J. (2002). Purchasing's Strategic Relevance. Journal of Purchasing \& Supply Management.

Narasimhan, R. and Das, A. (2001). The Impact of Purchasing Integration and Practices on Manufacturing Performance. Journal of Operations Management, 19, 593-609.

Pinkerton, R. L. (2001). The Evaluation of Purchasing to Supply Chain Management. In BURT, DAVID N. WORLD CLASS SUPPLY MANAGEMENT The Key To Supply Chain Management, Tata McGraw-Hill, India

Supply Chain Management: The Science of Better, Faster, Cheaper (January 2005). Federal Reserve Bank of Dallas. Retrieved January 15, 2006 from http://www.dallasfed.org/research/indepth/2005/id0501.html

http://www.pokharachamber.org.np/ 